\title{
Non-Evidentialist Epistemology: Introduction and Overview
}

\author{
Nikolaj Jang Lee Linding Pedersen and Luca Moretti
}

\section{Evidentialism and non-evidentialism}

The aim of this edited collection is to explore non-evidentialist epistemology or nonevidentialism - roughly, the view that evidence is not required in order for a doxastic attitude to have a positive epistemic standing. According to this view, it is possible for belief or acceptance to be epistemically justified, warranted, or rational in the absence of supporting evidence. To introduce non-evidentialist epistemology it is helpful to take a look at the contrasting view, evidentialism.

William K. Clifford is well-known—or infamous—-for espousing the thesis that it is always wrong to believe on insufficient evidence. ${ }^{1}$ This thesis is often referred to as 'Clifford's Thesis' or 'Clifford's Principle'. The thesis, as intended by Clifford, applies universally along several dimensions: for anyone, at any given time, and at any given place. The relevant kind of wrongness has been interpreted as both prudential and ethical. In this sense, evidence underwrites a prudential and ethical norm of belief. ${ }^{2}$

Evidentialism is a very prominent view in contemporary epistemology. Epistemic evidentialists draw inspiration from Clifford by endorsing an evidential norm for doxastic attitudes. However, unlike Clifford, evidentialists take evidence to underwrite an epistemic norm of belief. Their key commitment is thus the principle of epistemic evidentialism:

\footnotetext{
${ }^{1}$ See Clifford (1877/1999).

${ }^{2}$ See Chignell (2018).
} 
(EE) The epistemic status of a subject $S$ 's doxastic attitude towards any given proposition is determined by $S$ 's evidence.

(EE) can be found in a variety of incarnations. Focusing on justification, Earl Conee and Richard Feldman - the two most prominent advocates of evidentialism in contemporary epistemology_endorse the following version of (EE):

$\left(\mathrm{EE}_{\mathrm{CF}}\right)$ The epistemic status of a subject $S$ 's doxastic attitude towards a proposition $p$ at time $t$ is epistemically justified if and only if that particular attitude fits with the evidence that $S$ has at $t^{3}$

For Conee and Feldman, the relevant doxastic attitudes towards $p$ are belief, suspension of belief, and disbelief. Thus, $S$ 's belief is justified at a given time if and only if belief fits with $S$ 's evidence at that particular time. Similarly for suspension and disbelief. ${ }^{4}$

If evidential fit is understood in terms of evidential support, a reading of ( $\left.\mathrm{EE}_{\mathrm{CF}}\right)$ would be one according to which $S$ 's doxastic attitude is justified if and only if, on balance, that particular attitude is best supported by the evidence. Yet, Conee and Feldman are hesitant to commit to this reading of $\left(\mathrm{EE}_{\mathrm{CF}}\right)$. In particular, suppose that $S$ 's evidence barely supports $p$. As formulated, $\left(\mathrm{EE}_{\mathrm{CF}}\right)$ leaves it open whether, in such cases, belief and suspension are both

\footnotetext{
${ }^{3}$ Conee and Feldman (2004: 83). "Evidentialism", the chapter of this book that introduces (EE $\mathrm{CF}_{\text {) }}$, was originally published by Conee and Feldman in 1985 (Philosophical Studies, 48: 15-34).

${ }^{4}$ While Conee and Feldman's preferred evidentialist framework is put in terms of the full or outright attitudes of belief, suspension, and disbelief, they stress several times that evidentialism is likewise compatible with degrees of belief. See for instance Conee and Feldman (2004: 102).
} 
justified, or whether only one of the attitudes is. Conee and Feldman want this kind of openendedness in their formulation of evidentialism. ${ }^{5}$ It is worth noting that not understanding evidential fit as best on balance support still allows the evidentialist to state that, if a doxastic attitude of $S$ enjoys better support than other attitudes, then that is sufficient for that particular attitude to be justified. This is something that Conee and Feldman $d o$ want to endorse. ${ }^{6}$

$\left(E_{C F}\right)$ entails a supervenience thesis: justification strongly supervenes on evidence. ${ }^{7}$ This supervenience thesis is further elucidated by the following two theses, also defended by Conee and Feldman:

(S) The justificatory status of a person's doxastic attitudes strongly supervenes on the person's occurrent and dispositional mental states, events, and conditions.

(M) If any two possible individuals are exactly alike mentally, then they are alike justificationally, e.g., the same beliefs are justified for them to the same extent. ${ }^{8}$

(S) and (M) tell us that the evidential facts on which justificatory facts supervene are mental facts. Conee and Feldman's view is thus a form of mentalist evidentialism: the mental life of $S$ determines the justificatory status of the $S$ 's doxastic attitudes. In this sense their evidentialism

\footnotetext{
${ }^{5}$ See Conee and Feldman (2004: 102).

${ }^{6}$ See for instance Conee and Feldman (2004: 3).

${ }^{7}$ Cf. Conee and Feldman (2004: 101).

${ }^{8}$ Conee and Feldman (2004: 56). The chapter of this book that introduces (S) and (M) is "Internalism Defended", another key paper by Conee and Feldman (originally published in 2001 in H. Kornblith (ed.): Epistemology: Internalism and Externalism, 231-260. Oxford: Blackwell).
} 
is also a brand of internalist evidentialism: since all justificatory facts about $S$ 's doxastic attitudes pertain to the mental life of $S$, they are all internal facts.

Evidentialism accounts for the justification of $S$ 's doxastic attitudes towards any proposition. Hence, evidentialists are committed to taking an evidentialist line on $S$ 's doxastic attitudes towards perceptual propositions and anti-sceptical hypotheses (e.g., I'm not a brainin-a-vat) - thus maintaining that, in both cases, evidence must underwrite any positive epistemic standing enjoyed by $S$ 's doxastic attitudes. This observation is relevant for present purposes, as perceptual belief and anti-sceptical hypotheses are precisely two cases in which non-evidentialist views have been developed. However, some think that the epistemology of ordinary perceptual belief is not best accounted for in evidentialist terms. Others think that antisceptical hypotheses cannot be adequately treated within an evidentialist framework. Reflection on such cases make the prospects of non-evidentialist epistemology relevant. Here we introduce epistemic conservatism and hinge or cornerstone epistemology.

Advocates of epistemic conservatism endorse a version of the following principle:

(EC) If a subject $S$ believes that $p$, then this by itself confers a positive epistemic status upon $S$ 's belief that $p$.

Varieties of this view have been endorsed by a number of prominent philosophers and epistemologists, including Roderick Chisholm, Gilbert Harman, and William Lycan. ${ }^{9}$

\footnotetext{
${ }^{9}$ See Chisholm (1989), Harman (1986), and Lycan (1988). It is fair to say that Harman (1986) initially defines epistemic conservatism in terms of (EC), but then defends the weaker thesis that $S$ is justified in continuing to accept $p$ in the absence of a special reason not to. See more below.
} 
Conee and Feldman — arch-evidentialists, if anybody is — explicitly state that believing a proposition by itself is not evidence for its truth. ${ }^{10}$ If this is so, conservatism is a form of nonevidentialism. Indeed, epistemic conservatism would seem to conflict with evidentialism. Assuming that 'positive epistemic status' means 'justification' in the characterization of conservatism (EC), the conflict seems to surface. For, since believing that $p$ does not by itself qualify as evidence for $p$ by evidentialist lights, a belief that $p$ cannot on its own confer justification upon itself - contra conservatism. (A widely held constraint would appear to back this reasoning: $S$ 's belief that $p$ cannot serve as evidence for $S$ 's belief that $p$ because no belief can provide epistemic support for itself, on pain of vicious epistemic circularity.) Suppose, instead, that 'positive epistemic status' means 'any positive epistemic status relevant to justification'. In that case there still seems to be a prima facie tension—or, at least, from the evidentialist's perspective, the onus would be on the advocate of conservatism to provide an account of how belief on its own can confer any positive status relevant to justification without playing the role of evidence.

At this point it is important to observe that, strictly speaking, (EC) is a simplification. Most advocates of conservatism add a proviso to the thesis. Harman, for example, makes the positive epistemic status of believing that $p$ conditional on an absence of "a special reason not to". ${ }^{11}$ Furthermore, Lycan qualifies this positive epistemic status as a mere prima facie justification for believing $p .{ }^{12}$ Note, however, that even assuming the satisfaction of provisos like these, there would be nothing amounting to evidence to underwrite the belief that $p$. Within Conee and Feldman's evidentialist-mentalist framework this seems clear: just because there is

\footnotetext{
${ }^{10} \mathrm{Cf}$. Conee and Feldman (2008: 88).

${ }^{11}$ Harman (1986: 46).

${ }^{12}$ See Lycan (1988, Chap. 8).
} 
an absence of a reason not to believe that $p$, there need not be any mental states - conscious experience, beliefs, memories, or the like - that support the truth of $p$. And if no mental states like these are present, there is no justification for $p$, whether this is prima or ultima facie justification. Hence, at least on the face of it, epistemic conservatism is a non-evidentialist view.

Another prominent strand in non-evidentialist epistemology is hinge or cornerstone epistemology. This type of epistemology draws inspiration from Wittgenstein's On Certainty. Wittgenstein takes anti-sceptical hypotheses such as My cognitive capacities are functioning properly right now and I'm not currently having a vivid, coherent dream to be standing certainties. These are propositions exempt from doubt and which we have to take for granted without evidence because they are presuppositions of empirical enquiry, and because we cannot investigate everything, on pain of infinite regress. ${ }^{13}$

Due to their central role in our epistemic life, Wittgenstein likens anti-sceptical hypotheses to hinges: they are that which empirical investigation turns on, and must thus stay in place for such investigation to take place - just like the hinges must stay in place if we want to turn a door. ${ }^{14}$ Hence the label 'hinge epistemology'.

Recently, variants of hinge epistemologies have been articulated and developed in detail by Annalisa Coliva, Duncan Pritchard, and Crispin Wright. ${ }^{15}$ Like Wittgenstein, hinge epistemologists take on the task of providing a response to scepticism about the external world. And, like Wittgenstein, hinge epistemologists articulate their view by engaging to a considerable extent with G. E. Moore's common-sense response to scepticism.

Moore famously (or infamously) claimed to give a rigorous proof of the existence of the external world by reasoning along the following lines: here is one hand (while gesturing

\footnotetext{
${ }^{13}$ Cf. Wittgenstein (1969: §§341-343).

${ }^{14}$ Cf. Wittgenstein (1969: §341, §343).

${ }^{15}$ See mainly Coliva (2015), Pritchard (2012, 2015), Wright (2003a, 2004, 2014).
} 
with one hand), and here is another (while gesturing with the other)—so, there is an external world! ${ }^{16}$

Many do not share Moore's own optimism about the cogency of his 'proof'. Wright is widely credited with a particularly insightful diagnosis of why Moore's Proof is not cogent: it is subject to warrant transmission failure (or 'transmission failure', in short). We introduce this notion below. In addition to shedding light on the views of hinge epistemologists about the structure of warrant, transmission failure will help us appreciate why hinge epistemologists are committed to giving a non-evidentialist account of the positive epistemic status of hinges.

Wright — and following him, Coliva and Pritchard — give the following rational reconstruction of Moore's argument:

\section{Moore's Proof:}

(I) My evidence is in all respects as if I have hands.

So, (IIa) I have hands.

(IIb) If I have hands, then there is an external world (i.e. something external to my mind).

So, (III) There is an external world

Many epistemologists find this I-II-III argument unpersuasive. Why does it misfire? Hinge epistemologists grant that (IIb) is unproblematic. It enjoys the status of being a conceptual truth. After all, it is part of our ordinary conception of hands that they are things extended in time and space- that is, they are not just in our minds. The non-deductive

\footnotetext{
${ }^{16}$ Cf. Moore (1939).
} 
transition from (I) to (IIa), however, is problematic. This is where transmission failure becomes relevant. Wright embraces the following principle of warrant transmission failure:

$\left(\mathrm{WTF}_{\mathrm{W}}\right) \quad$ Let the argument from $p_{1}, \ldots, p_{n}$ to $c$ be valid. Warrant for $p_{1}, \ldots, p_{n}$ is transmitted to $c$ only if $p_{1}, \ldots, p_{n}$ can be warranted antecedently to and independently of any warrant for $c .^{17}$

Coliva favours a version of the principle where 'any warrant to accept $c$ ' is replaced by 'the assumption of $c^{\prime}$ :

$\left(\mathrm{WTF}_{\mathrm{C}}\right) \quad$ Let the argument from $p_{1}, \ldots, p_{n}$ to $c$ be valid. Warrant for $p_{1}, \ldots, p_{n}$ is transmitted to $c$ only if $p_{1}, \ldots, p_{n}$ can be warranted antecedently to and independently of the assumption of $c .^{18}$

$\left(\mathrm{WTF}_{\mathrm{W}}\right)$ and $\left(\mathrm{WTF}_{\mathrm{C}}\right)$ have a common denominator: transmission of warrant from the premises to the conclusion of an argument is held hostage to the warrant for the premises' being independent of the warrant for, or the assumption of, the conclusion. In case the relevant kind of independence is absent, warrant fails to transmit because the warrant of at least one of the premises presupposes warrant for, or the assumption of, the conclusion. In this sense transmission failure instantiates a certain type of epistemic circularity.

In Moore's Proof, while the argument from (IIa) and (IIb) to (III) is logically valid (it is an instance of modus ponens), (IIa) cannot be warranted by (I) independently of (III) in the

\footnotetext{
${ }^{17}$ Cf. Wright (2002: 332), (2003b: 57), (2004: 172), (2007: 36).

${ }^{18}$ Cf. Coliva (2015: 93).
} 
sense specified by $\left(\mathrm{WTF}_{\mathrm{W}}\right)$ or $\left(\mathrm{WTF}_{\mathrm{C}}\right)$. According to Wright, this epistemic dependence is in place because, in the absence of an antecedent and independent warrant for thinking that there is an external world, there is no reason to think that experience represents, rather than misrepresents, one's environment. Thus, absent antecedent warrant for (III), (I) cannot have evidential force and fails to provide a warrant for (IIa). For Coliva, following $\left(\mathrm{WTF}_{\mathrm{C}}\right)$, the diagnosis of transmission failure is put in terms of assumption of (III) rather than antecedent Warrant for (III). ${ }^{19}$

We thus see that hinge epistemologists, such as Wright and Coliva, deem Moore's Proof defective because it falls prey to a certain kind of epistemic circularity. This conclusion helps us appreciate why they are driven towards a non-evidentialist epistemology.

Moore's Proof is an attempt to show that the belief that there is an external world enjoys a positive epistemic status of an evidential kind - that this belief is warranted or justified on the basis of evidence. If asked "Why are you warranted or justified in believing that there is an external world?", the Moorean would respond, "Because I have hands, and if I have hands, then there is an external world." (IIa) and (IIb) in Moore's Proof are meant to constitute evidence for (III).

Transmission failure undermines this. Thus, Moore's attempt to establish that belief in an external world has an evidential positive epistemic status is unsuccessful by the lights of hinge epistemologists. However, hinge epistemologists think that the Moorean failure goes even further: it generalizes to Moore-style 'proofs' for other anti-sceptical hypotheses (for

\footnotetext{
${ }^{19}$ Wright and Coliva's transmission failure diagnoses is rejected by the so-called dogmatists (or liberals) - Pryor (2000 and 2004) being a prominent example. According to the dogmatist (or the liberal), if (I) is thought of as the experience that I have hand, this experience by itself suffices to prima facie warrant (IIa).
} 
instance: I'm not a brain in a vat, my cognitive capacities are functioning properly right now; I'm not currently having a vivid, coherent dream, etc.).

Putting the point schematically, this is the structure of any I-II-III argument:

(I) My evidence is in all respects as if $p$.

So, (IIa) $p$.

(IIb) If $p$, then $c$.

So, (III) $c$.

Any argument satisfying the above schema fails to transmit warrant, when $p$ is some empirical world proposition that entails a correlated anti-sceptical hypothesis $c$.

Why? Because-using Wright's terminology—anti-sceptical hypotheses are authenticity-conditions for empirical enquiry. They pertain to the suitability of the attendant circumstances for enquiry about the empirical world. ${ }^{20}$ But, as seen, this kind of suitability is precisely what must be assumed (Coliva) or warranted (Wright) in order for the non-deductive transition from (I) to (IIa) to be validated. Thus, any I-II-III argument fails to transmit warrant according to hinge epistemologists - meaning that any I-II-III argument fails to deliver an evidential positive epistemic status for anti-sceptical hypotheses.

Now we are just one step away from the conclusion that hinge epistemologists are nonevidentialists about anti-sceptical hypotheses. The last step to reach this conclusion is the observation that hinge epistemologists take I-II-III arguments to exemplify the best attempts to establish an evidential positive epistemic status for anti-sceptical hypotheses. Since the best

\footnotetext{
${ }^{20}$ This terminology is used in Wright $(2007,2014)$. Elsewhere Wright characterizes the warrantability of the transition from (I) to (IIa) as 'information-dependent'. See Wright $(2002,2004)$.
} 
attempts fail, any attempt will fail and, so, anti-sceptical hypotheses cannot enjoy an evidential positive epistemic status. ${ }^{21}$ The hinges, as it were, cannot be supported by evidence. Hinge epistemology is thus a form of non-evidentialist epistemology.

What do non-evidentialist hinge epistemologists such as Wright, Coliva, and Pritchard say about the positive epistemic status of hinges? Let us consider each of their accounts in turn, albeit very briefly.

Wright introduces and characterises a non-evidential type of warrant which he calls 'epistemic entitlement'. In fact, he introduces four notions of entitlement: strategic entitlement, entitlement of cognitive project, entitlement of substance, and entitlement of rational deliberation. Here we introduce only entitlement of cognitive project and strategic entitlement - the kinds of entitlement that are relevant for the purposes of this edited collection. ${ }^{22}$

This is how Wright characterizes entitlement of cognitive project.

A subject $S$ with a given cognitive project $C P$ is entitled to accept a proposition $p$ if

(i) $\quad p$ is a presupposition of $C P$, i.e. if to doubt $p$ (in advance) - or weaker: being open-minded about $p$-would rationally commit one to doubting (or being

\footnotetext{
${ }^{21}$ See Wright (2004: 170-171).

${ }^{22}$ For details regarding the two other species of entitlement, see Wright (2004). Additionally, Wright (2014) offers an extensive discussion of strategic entitlement and several issues pertaining to entitlement in general. Wright-style entitlement is not to be conflated with what Tyler Burge calls 'epistemic entitlement', which he has used to give an account of testimonial and perceptual warrant (1993, 2003, 2020). For comparison between Wrightian and Burgean entitlement, see Graham and Pedersen (2020b) and Wright (2014, Sect. 11.2).
} 
open-minded about) the significance of $C P$;

(ii) there is no sufficient reason to believe that $p$ is untrue; and

(iii) any attempt to acquire an evidential warrant for $p$ would involve epistemic circularity or infinite regress. ${ }^{23}$

According to Wright, familiar anti-sceptical hypotheses such as There is an external world and I'm not a brain in a vat are entitlements for cognitive projects concerning the empirical world.

The significance of cognitive projects pertaining to the empirical world is to learn something about the world - that is, to acquire true beliefs about the world. It appears that antisceptical hypotheses are presuppositions of such cognitive projects in the sense of clause (i). Consider There is an external world. Suppose your friends tell you that your suitcase must weigh more than 9 kilos because you told them that you packed a hardback version of Plato's collected works. You decide to check whether they are right. Now you have a cognitive project: to determine the weight of your suitcase. It would seem that if you doubt or are open-minded about whether there is an external world, you are rationally committed to doubting the significance of this project. $^{24}$

Clause (ii) of Wright's characterization is a no defeater clause. Sufficient countervailing evidence would defeat entitlement. Certainly, there is no sufficient evidence for believing that There is an external world is untrue.

\footnotetext{
${ }^{23}$ Cf. Wright (2004: 191-192).

${ }^{24}$ Suitcases are objects in the external reality-i.e. outside your mind. So, if you doubt or are openminded about whether such a reality exists, it seems that you are rationally committed to doubting or being open-minded about whether you can indeed learn anything about your suitcase - an object in external reality.
} 
Clause (iii) captures the idea that $p$ cannot be supported by evidence as a matter of principle. As seen in the I-II-III argument, according to Wright, any attempt to acquire an evidential warrant to accept a proposition like There is an external world is bound to misfire. This failure is not a contingent but principled failure. Why? Because, as seen, such an attempt will presuppose that there is an antecedent warrant for thinking that There is an external world and thus will be subject to transmission of warrant failure, i.e. a certain kind of epistemic circularity. ${ }^{25}$

In conclusion, since There is an external world satisfies (i)-(iii), it appears to be an entitlement for cognitive projects concerning the empirical world. This line of reasoning is extendable to other familiar anti-sceptical hypotheses such as I'm not a brain in a vat and I'm not currently having a vivid, coherent dream-meaning that they, too, are candidate entitlements of cognitive project.

The basic idea behind strategic entitlement is that accepting hinges has good epistemic consequences. Strategic entitlement is thus explicitly consequentialist in nature. Wright deploys the game-theoretic notion of a dominant strategy to spell out exactly in what sense hinge acceptance has good epistemic consequences. In our present context we can understand this notion as follows: for a given project, a range of strategies $s_{1}, \ldots, s_{\mathrm{n}}$ for executing this project, and states of the world $w_{1}, \ldots, w_{\mathrm{k}}$, a strategy $s_{\mathrm{i}}(1 \leq i \leq n)$ is a dominant strategy if and only if it does at least as well as every other strategy for any state of the world and for at least one state it does better.

\footnotetext{
${ }^{25}$ Similarly, if it would take an infinite chain of justificatory projects to acquire an evidential to accept $p$, doing so would seem to be beyond our epistemic reach. After all, we are finite beings and cannot execute an infinite number of projects.
} 
Wright applies this idea to combat inductive scepticism, i.e. scepticism targeting the following claim:

(IND) Inductive methods are truth-conductive. ${ }^{26}$

He argues that we are strategically entitled to (IND) because there is no sufficient reason to think that (IND) is untrue, it is epistemically valuable to form many true beliefs about the future, and accepting (IND) and so executing projects concerning the world using inductive methods is a dominant strategy. For, if the world is regular, accepting (IND) and investigating the world yields many true beliefs about the future — which is epistemic valuable — while the strategy of not accepting (IND) and not executing projects results in only a few beliefs - and so, at most only few true beliefs. On the other hand, if the world is not regular, accepting (IND) and investigating the world using inductive methods does not yield many true beliefs about the future. However, the same point applies to the strategy of not accepting (IND) and not executing. Hence, accepting (IND) and executing projects about the world is a dominant strategy.

Interestingly, the same kind of considerations apply to There is an external world, I'm not a brain in a vat, and other familiar anti-sceptical hypotheses concerning the empirical world. ${ }^{27}$ There is no sufficient reason to think such hypotheses false, it is epistemically valuable to have many true beliefs about the world, and accepting these anti-sceptical hypotheses and executing cognitive projects about the world is a dominant strategy. So it seems that we are strategically entitled to accept all these anti-sceptical hypotheses.

\footnotetext{
${ }^{26}$ Cf. Wright (2004, Sect. III). See Wright (2014) for further discussion.

${ }^{27}$ Cf. Wright (2004: 192).
} 
Let us focus again on There is an external world. If there is indeed an external world, accepting that there is an external world and executing relevant cognitive projects yields many true beliefs about the world, whereas not accepting the anti-sceptical hypothesis and not executing does not. On the other hand, if the external world does not exist, accepting that it does and executing relevant cognitive projects fails to yield many true beliefs. But, again, the same point applies to the strategy of not accepting that there is an external world and not executing cognitive projects. Thus, accepting There is an external world and executing relevant cognitive projects is a dominant strategy. Since the other conditions for strategic entitlement are met, we strategically entitled to accept There is an external world.

The conditions that Wright proposes for entitlement of cognitive project and strategic entitlement are sufficient for warrant. None of these condition require the presence of positive evidence supporting $p$, and hence, entitlement — whether of cognitive project or strategic — is a non-evidential species of warrant. This turns the tables on the sceptic. While conceding that there can be no such thing as evidence supporting hinges, Wright denies that there must be evidence in order for hinge acceptance to be warranted. Entitlement of cognitive project and strategic entitlement are meant to be complementary proposals that spell out what nonevidential species of warrant may look like.

How about Coliva? According to Coliva, the positive epistemic status of being warranted is constitutively tied to truth and evidence. Hence, according to her, hinges are notand, indeed, cannot-be warranted. ${ }^{28}$ Instead, she argues, hinge acceptance is extendedly rational.

\footnotetext{
${ }^{28}$ Cf. Coliva (2015: 68-69). Wright $(2003,2004,2014)$, as we have seen, endorses a species of nonevidential warrant. Coliva and Wright thus have a substantial disagreement concerning the term 'warrant'. However, at the same time they are also in substantial agreement because they both accord a non-evidential, positive epistemic status to hinge acceptance.
} 
Extended rationality contrasts with narrow rationality. The latter-but not the former - requires evidence. ${ }^{29}$ Our ordinary perceptual beliefs are narrowly rational, for their being true is supported by the evidence from our senses. However, since extended rationality is non-evidential in nature, the same story cannot apply to hinges. In what sense, then, is hinge acceptance rational? Coliva's answer is that such acceptance is constitutive of our epistemic life and practice.

The rules of chess are constitutive of the game of chess. Without these rules there simply is no such thing as playing games of chess. Assumption of hinge propositions bears a similar relation to our epistemic life and practice. Hinges must be assumed in empirical enquiry if such enquiry is to result in the acquisition of evidence and warrant, as hinges ground the very possibility of sensory experience to qualify as evidence for empirical propositions and, thus, for such propositions to be warranted. ${ }^{30}$ Even more fundamentally, investigation of the empirical world could not even start without the assumption of hinge propositions. In these ways, much like the rules of chess are constitutive of the game of chess, assumption of hinges is constitutive of our epistemic life and practice. ${ }^{31}$

Pritchard, like Wright and Coliva, is a hinge epistemologist. However, while Wright and Coliva take hinges to be respectively entitled and extendedly rational for us (i.e. they enjoy a positive epistemic status), Pritchard takes the hinges to lie outside the scope of epistemic evaluation. In this regard, he is closer to the ideas expressed in On Certainty since Wittgenstein, too, took hinges to be thus located.

\footnotetext{
${ }^{29}$ Cf. Coliva (2015: 129-130).

${ }^{30}$ Again, this is because Coliva takes warrant to be constitutively tied to evidence and truth.

${ }^{31}$ Coliva (2015, Chap. 4).
} 
Pritchard's work offers an interesting, useful taxonomy of hinges. ${ }^{32}$ Following Wittgenstein, he takes some hinges to be personal. For example, I'm a US resident is a hinge for Bob's project of figuring out what his social security number is. Personal hinges are very local since, by definition, they pertain only to enquiry regarding a single person. Familiar antisceptical hypotheses are hinges of a more general sort. There is an external world is a hinge for anybody who investigates the empirical world. Anti-sceptical hypotheses are thus hinges for a very large class of projects. However, while anti-sceptical hypotheses are more general than personal hinges, they are nonetheless still local in a clear sense: they do not pertain to enquiry in general. While There is an external world is a hinge for enquiry concerning the empirical world, it is not a hinge of a priori reasoning - say, figuring out whether there are infinitely many prime numbers. In light of these observations, Pritchard introduces a third kind of hinge: the über hinge. The über hinge is meant to be the most general kind of hingesomething that entails other, less general hinges and which is presupposed in all enquiry. His candidate for the über hinge propositions is I'm not radically and fundamentally mistaken about in my beliefs. Personal hinges and familiar anti-sceptical hypotheses are all particular or local manifestations of this completely general hinge in that they are entailed by it. ${ }^{33}$

Since the über hinge lies outside the domain of epistemic evaluation, it is neither rational nor irrational, and it is neither warranted nor unwarranted. It is a-rational and $a$ warranted. As such, because the über hinge is presupposed in all enquiry, our believing is groundless.

So far, so good. We have introduced the views of Wright, Coliva, and Pritchard, three prominent hinge epistemologists in contemporary epistemology. Before moving on to the

\footnotetext{
${ }^{32}$ See Pritchard (2015, Sect. 4.2).

${ }^{33}$ See Pritchard (2015: 95-96).
} 
summaries of the individual contributions to this volume let us briefly sketch some challenges faced by hinge epistemologists: the epistemic reasons and rationality challenge and the leaching problem. This will help set up some of the contributions to the volume.

Let us turn first to the epistemic reasons and rationality challenge. Consider respectively evidential and non-evidential positive statuses and ask whether doxastic attitudes that have such statuses are supported by epistemic reasons and are epistemically rational. For the evidential case the answer seems straightforwardly affirmative. To illustrate suppose, for example, that you have proved that there are infinitely many primes and believe so on that basis. In that case your belief enjoys a positive epistemic status of an evidential kind (justification for Wright, ${ }^{34}$ narrow rationality and warrant for Coliva). Is your belief supported by an epistemic reason and is it epistemically rational? Yes, your proof - the evidenceconstitutes an epistemic reason and since you hold your belief on the basis of such a reason, your belief is epistemically rational. This line of reasoning should hardly come as a surprise, since the presence of evidence supports the truth of your belief - and truth is widely considered to be an epistemic good. The challenge for non-evidentialism comes into focus when it is added to this observation that many epistemologists take truth to be the only fundamental epistemic good. ${ }^{35}$ For, given the principled absence of evidence, how could the non-evidentialist tell a story about how their favoured non-evidential, positive epistemic status connects the acceptance of hinges to truth, the only fundamental epistemic good? Now, if the nonevidentialist concedes that our reasons to accept hinges are actually pragmatic in nature (e.g., that not doing so would lead to practical paralysis), the force of non-evidentialism as a response

\footnotetext{
${ }^{34}$ Wright calls 'justification' evidence-based warrant.

${ }^{35}$ The view is very widespread although it is often left implicit or only stated in passing. Some sample references include BonJour (1985); Burge (2003); David (2001, 2005); and Goldman (2001).
} 
to scepticism would seem to vanish. The sceptical challenge, after all, is an epistemic challenge and, as such, addressing it by appealing to pragmatic considerations seems to be fundamentally misguided. ${ }^{36}$

Let us turn to the leaching problem. According to hinge epistemologists, anti-sceptical hypotheses enjoy either a non-evidential, positive epistemic status (Wright and Coliva) or no epistemic status at all (Pritchard). Ordinary propositions, on the other hand, enjoy a positive, evidential status. However, does not the weaker epistemic status of hinges or the complete absence of such a status threaten to encroach on the robust domain of evidential positive statuses enjoyed by ordinary beliefs? In other words, how could ordinary propositions be justified by evidence if the propositions on which the justifying force of this evidence depends — the hinges - are not evidentially justified themselves? One might feel that the hinge epistemologist should grant that the epistemic status of ordinary beliefs is downgraded to mere entitlement (Wright), extended rationality (Coliva), or no positive epistemic status at all (Pritchard). ${ }^{37}$

\footnotetext{
${ }^{36}$ See Pritchard (2005), Jenkins (2007), and Pedersen $(2009,2020)$ for presentation and discussion of these issues. See also Wright (2014). Note that Pritchard would deny the relevance of this challenge to his view—but not Wright and Coliva's views — as he takes the über hinge to lie outside the domain of epistemic evaluation.

${ }^{37}$ The epistemic leaching problem is discussed by Wright (2004: 207-210). Interestingly, Wright attributes a particularly sharp formulation of the problem to Moruzzi (see Wright 2004: 208, n. 26). Wright only discusses the issue in terms of entitlement. However, it would seem that leaching presents at least a prima facie challenge to any view committed to according a weaker-or no-positive epistemic status to hinges.
} 


\section{Volume Overview}

Let us now turn to the contributions to this volume and see how, in different ways, they explore issues or questions related to non-evidentialist epistemology. The volume is divided into three parts: the first focuses on hinge epistemology, the second offers critical reflections on evidentialism, and the third deals with extension of non-evidentialist epistemology.

\section{Part I: Hinge Epistemology}

The first part of the volume contains contributions by Luca Zanetti, Sebastiano Moruzzi, Natalie Ashton, Annalisa Coliva, Luca Moretti, and Junyeol Kim. All contributions engage directly with issues or questions related to hinge epistemology.

Luca Zanetti ("Inescapable hinges: a transcendental hinge epistemology”, Chap. 2) draws a distinction between escapable and inescapable hinges and uses this distinction to frame his discussion of hinge epistemology. Inescapable hinges are hinges that are immune to doubt. They cannot coherently be rationally doubted because subjecting an inescapable hinge to doubt will inevitably presuppose that very hinge. Escapable hinges are hinges that do not have this feature. Zanetti brings this distinction to bear on the discussion of scepticism by arguing that familiar anti-sceptical hypotheses only qualify as escapable hinges. Consider the hypothesis I'm not a brain in a vat. It does not seem that, in doubting this hypothesis, one has to presuppose it or take it to be true. For example, one well-known sceptical argument - the argument from underdetermination - proceeds from the premise that being a brain in a vat leaves sensory experience untouched. Thus, one wouldn't be able to tell the difference between being in a sceptical scenario and being in non-sceptical scenario. In rehearsing this line of reasoning, it would seem that one does not have to presuppose that one is not a brain in a vat.

The classification of familiar sceptical hypotheses as escapable is significant. Besides being interesting in its own right, it bears on the anti-sceptical import of the hinge 
epistemologies put forward by Wright, Coliva, and Pritchard. Zanetti argues that Coliva and Wright focus on escapable hinges and, as a result, their hinge epistemologies are local and do not pertain to cognition in general. For this reason Zanetti takes these views to have limited anti-sceptical import: the positive epistemic status that hinges can enjoy is conditional at best. Focusing on Coliva, Zanetti also argues that, on her view, hinges have a positive epistemic status_-i.e. they are extendedly rational—only if one engages in empirical enquiry. However, Zanetti notices that one might not do so. After all, there is no epistemic mandate to do so. Coliva argues that one has pragmatic reason not to opt out of empirical enquiry. Zanetti responds that it is misguided to respond to an epistemic challenge by adducing pragmatic reasons. Zanetti likewise argues against Pritchard's hinge epistemology, according to which hinge propositions lie outside the domain of epistemic evaluation. Zanetti considers Pritchard's über hinge - that is to say, I'm not fundamentally and radically mistaken in my beliefs. As said, Pritchard takes this to be an über hinge because it encodes - and entails - the negations of many familiar sceptical hypotheses. Zanetti contends that Prichard does not successfully show that the über hinge lies outside the domain of epistemic evaluation. In this contribution, Zanetti also takes preliminary steps to formulate a hinge epistemological view that focuses on inescapable hinges. He takes There is at least one truth and I'm not entirely wrong in my judgments to be plausible candidates for hinges that are inescapable for cognition in general. Since any inescapable hinge is beyond — or transcends — doubt, Zanetti calls a view of this type 'transcendental hinge epistemology'.

Natalie Ashton (“Extended Rationality and Epistemic Relativism”, Chap. 3) examines whether Coliva's version of hinge epistemology - the extended rationality view-is compatible with epistemic relativism. According to Coliva, a challenge for the relativist is to show that alternative, equally valid and incompatible belief-forming practices about the world are possible. Coliva grants that if this can be shown, extended rationality and relativism are 
compatible. However, Coliva argues that there can be no alternative, equally valid practice to our basic practice of forming beliefs about a world consisting of mind-independent objects through perception. She takes it that there are two ways one could try to argue for the existence of an alternative practice: either by keeping the basic practice of perception fixed and adopting an alternative conception of the world, or by replacing the basic practice of perception with another practice while keeping our conception of the world fixed. Coliva contends, however, that both paths are unviable. She argues that the former path is inconceivable. For it would have to involve subjects who form beliefs about the world without perception, and so through rational intuition or something like it. Coliva argues that the second path is unintelligible because it would amount to some form of phenomenalism, which cannot make proper sense of the content of experience. Drawing on the work of David Chalmers, Ashton introduces several notions of conceivability and contends that Coliva has not shown that they fail to apply to the idea of belief formation about a mind-independent world through rational intuition. Indeed, she argues, some of them do apply. Against the contention that phenomenalism makes experience unintelligible, Ahston highlights that Coliva's understanding of experience draws on the work of Tyler Burge, who takes experience to be of an objective, mind-independent reality. Ahston contends that this commits Coliva to using core ideas from our epistemic system as a standard of evaluation for the phenomenalist framework. This neglects the assumption that alternative, incompatible systems are incommensurable and do not allow for such cross-systematic evaluation. Ahston concludes that Coliva has established neither that the first nor the second relativist path is a no-go. She goes on to sketch what other paths might be available - and suitable — as relativist starting points.

Sebastiano Moruzzi (“The Alethic Leaching Problem for Hinge Epistemology”, Chap. 4) explores the nature of truth within the framework of hinge epistemology. Coliva has recently formulated the alethic challenge to hinge epistemologies which build in the assumption that 
hinges are propositions and thus truth-apt. ${ }^{38}$ The challenge is roughly this: if hinges are truthapt and the truth property applicable to hinges is a substantial (i.e. non-deflationary), this truth (or falsity) is determined by either mind-dependent or mind-independent facts. However, neither option is viable, and thus there is no substantial truth property applicable to hinges. One might then infer from this that hinges are not truth-apt — contra the view that hinges are propositions. Coliva's response is to reject the assumption that the truth property applicable to hinges is substantial, thus embracing a deflationary account of hinge truth. She combines this with the thesis that ordinary propositions about the empirical world are instead true substantially in virtue of corresponding to reality. Since hinge propositions and ordinary propositions are true in different ways, Coliva's hinge epistemology incorporates a form of alethic pluralism. Moruzzi raises two challenges to the alethic commitments of Coliva's view. According to the integration challenge, the alethic-pluralist hinge epistemologist must show how to integrate a form of deflationism into the combined framework of alethic pluralism and hinge epistemology. According to the alethic leaching problem, the alethic-pluralist hinge epistemologist must show that the deflationary truth property of hinges and the robust correspondence property of ordinary propositions can be kept apart. (This is an alethic version of the epistemic leaching problem described above.) Moruzzi concedes that versions of alethic pluralism are available to the hinge epistemologist to address either challenges. However, he argues that no single version, or no coherent set of versions, of alethic pluralism can address both challenges. Moruzzi concludes that hinge epistemologists can only incorporate deflationism into their framework by adopting deflationist monism-meaning that hinge

\footnotetext{
${ }^{38}$ See Coliva (2018). The truth-aptitude of hinges runs counter to Wittgenstein's own view in On Certainty and the line taken by philosophers of Wittgenstein such as Moyal-Sharrock (2004).
} 
epistemologists cannot adopt a form of alethic pluralism involving deflationism, contra Coliva's proposal.

Annalisa Coliva (“Hinges, radical scepticism, relativism and alethic pluralism”, Chap. 5) responds to the challenges presented by Zanetti, Moruzzi, and Ashton. In response to Zanetti, Coliva resists his push towards transcendental hinge epistemology by denying that there is such a thing as a completely global sceptical doubt and a completely general hinge proposition presupposed in all enquiry. For her, enquiry—no matter how general—is always constrained by specific, local hinges. Zanetti grants that there can be no evidential support for the truth of hinges, including inescapable hinges. Coliva argues that this severely threatens the prospects of transcendental hinge epistemology. In response to Ashton's criticism of her challenge to relativism, Coliva speaks further to both the issue of conceivability and the issue of unintelligibility. She argues that, even if beings provided with rational intuition of a mindindependent world are conceivable, such beings would tell us nothing about an alternative belief system entertained by beings sufficiently like us—so, this conceivability does not sustain any interesting form of relativism. Coliva adds that, despite the different belief-forming practice of these beings, their beliefs about the world would by design be the same as oursso, their system would not exhibit the incompatibility with our system, required to get genuine relativism. In response to Ashton's objections to her unintelligibility argument, Coliva clarifies that even if phenomenalism is intelligible, the real issue is whether phenomenalism is relevant to the possibility of relativism because it is actually tenable. Coliva denies this. By the same token, she also questions Ashton's appeal to incommensurability as irrelevant, for she takes incommensurability-involving relativism to be untenable. In response to Moruzzi, Coliva questions his conclusion that there is no version of alethic pluralism available to the hinge epistemologists that can be used to address both the integration challenge and alethic leaching problem. According to Coliva, there is such a version of alethic pluralism available to the hinge 
epistemologist - namely, one that categorizes hinge propositions as being plainly true and ordinary propositions as being true in virtue of correspondence (or some other more robust property). Coliva adopts the notion of plain truth from Michael P. Lynch, one of the most prominent advocates of alethic pluralism. A proposition is plainly true if and only if, unlike ordinary propositions about the world, there is no distinct property — such as correspondencethat grounds its truth. ${ }^{39}$ For instance, the truth of the proposition that Mt. Everest is more than $8,000 \mathrm{~m}$ high is grounded in its corresponding to reality. Hinges, on the other hand, are just true - they simply have the truth property characterized by the Equivalence Schema ("It is true that $p$ if and only if $p ")$ and other core principles about truth. According to Coliva, plain truth is sufficiently deflated to qualify as deflationary truth and can be incorporated into an alethic pluralist framework which the hinge epistemologists can help themselves to. This same framework can be used to address the alethic leaching problem. According to Coliva, when asked what property is preserved in entailments between ordinary propositions and antisceptical hypotheses, the answer is plain: plain truth.

Luca Moretti ("Problems for Wright's entitlement theory”, Chap. 6) scrutinises and criticises Crispin Wright's entitlement theory. As we have seen, Wright holds that we have various types of non-evidential warrant—which he calls "epistemic entitlement" or simply "entitlement"-for accepting hinge propositions (or "cornerstones", as he calls them). Entitlement theory is meant by Wright to deliver a forceful response to the sceptic who argues that we cannot rationally claim warrant for our ordinary beliefs about the world because we fail to be warranted in accepting hinges. Moretti initially focuses on strategic entitlement, which is one of the types of entitlement described in detail by Wright. We have seen that this

\footnotetext{
${ }^{39}$ See Lynch (2009: 90). The characterization provided here is not exactly the one provided by Lynch but it will do for present purposes.
} 
type of entitlement is explicitly game-theoretic in nature. Moretti rehearses a criticism originally due to Pedersen (2009) of the game-theoretic defence of strategic entitlement: this defence crucially presupposes veritic monism (i.e. truth is the sole thing of intrinsically epistemic value), which is less plausible and less popular than veritic dual goal monism (i.e. truth and the absence of falsehood are the sole things of intrinsic epistemic value). Then, Moretti criticises the game-theoretic defence of strategic entitlement (suggested but not endorsed by Pedersen himself): this defence presupposes a form of epistemic pluralism about values, which is not necessarily preferable to veritic dual goal monism. After this, Moretti focuses on Wright's general notion of entitlement as non-evidential justification. He contends that, in important cases, non-evidential justification for accepting a cornerstone cannot secure evidential justification for believing correlated ordinary propositions. For the epistemic risk of accepting the cornerstone does transmit to ordinary propositions. His argument rests on a probabilistic regimentation of the epistemic leaching problem.

Junyeol Kim (“Epistemic Entitlement: Intellectual Desires and Epistemic Rationality”, Chap. 7) likewise engages critically with Wright's entitlement theory. Kim argues that Wright's conception of epistemic entitlement — specifically of entitlement of cognitive project-implies the controversial thesis that epistemic rationality or justification depends on the subject $S$ 's intellectual desires, such as the desire for knowledge. Kim further argues that Pedersen's teleological account of epistemic entitlement vindicates this thesis. ${ }^{40}$ Pedersen's account adopts a realization-independent conception of teleological value: something $X$ has teleological value just in case it has value in virtue of being aimed at something else $Y$ of value, even if $Y$ is not realized in the actual world. Pedersen's account says that if $S$ is entitled to accept a presupposition $p$ of a cognitive project, $S$ has an epistemic reason to do so because

\footnotetext{
${ }^{40}$ See Pedersen (2009).
} 
such acceptance has a realization-independent epistemic teleological value. For it aims at the epistemic goal of the cognitive project—generally, at acquiring knowledge. Kim suggests that if $S$ has justification for believing an ordinary proposition $q, S$ is entitled to accept some presupposition $p$ of the relevant epistemic project. But if $S$ is entitled to accept $p, S$ must then desire to acquire the epistemic goal of the epistemic project of $p$. This shows the dependence of our epistemic justification on our intellectual desires. In general, $S$ 's epistemic rationality or justification depends on $S$ 's desire for knowledge. In the final part of the paper, Kim discuses implications of his finding. Interestingly, he notices that epistemic entitlement does not reduce epistemic justification or rationality to instrumental rationality, but rather puts a hierarchical relation between epistemic and instrumental rationality, such that the former rests on the latter.

\section{Part II: Critical Reflections on Evidentialism}

The second part of this volume features chapters by Kevin McCain and Tommaso Piazza. They both engage critically with the evidentialism of Conee and Feldman.

Kevin McCain (“Epistemic Conservatism: A Non-Evidentialist Epistemology?” Chap. 8) focuses on epistemic conservatism - the view that merely having a belief confers some positive epistemic status on the content of that belief. McCain explores the question whether epistemic conservatism and evidentialism are compatible. As noted in the first section of this introduction, they are often regarded as being in tension or even outright conflict—-something that is especially clear within Conee and Feldman's framework because they explicitly say, contra conservatism, that believing a proposition cannot by itself be evidence for its truth. ${ }^{41}$ McCain, however, argues that the tension is only apparent: epistemic conservatism and

\footnotetext{
${ }^{41}$ Cf. Conee and Feldman (2008: 88).
} 
evidentialism turn out to be compatible. Embracing epistemic conservatism thus does not commit one to a form of non-evidentialism. Interestingly, McCain also suggests that this fact can help evidentialism in the struggle with scepticism. More specifically, McCain defends a version of epistemic conservatism, endorsed by Chisholm, Elgin and Lycan, according to which, if $S$ believes $p$ at $t$, then $S$ thereby has minimal positive evidence for $p$ at $t$. This evidence is insufficient for justification (arguably, withholding is what is justified), but it does make believing $p$ for $S$ more reasonable than disbelieving it. Evidentialism, on the other hand, holds that believing $p$ is epistemically justified for $S$ at $t$ if and only if it fits the evidence $S$ has at $t$. Epistemic conservatism would be inconsistent with evidentialism just in case it stated that $S$ can be justified in believing that $p$ at $t$ even if $p$ does not fit S's evidence at $t$. But McCain forcefully argues that there is no inconsistency because S's believing that $p$ does count as evidence for $\mathrm{S}$ in support of $p$. As said, McCain also suggests that epistemic conservatism can be useful to respond to various sceptical challenge. Perhaps the most representative of these changes concerns external world scepticism. According to McCain, evidentialists typically responds to this challenge by adducing an inference to the best explanation: the real-world hypothesis explains our data better than any sceptical hypothesis. epistemic conservatism is useful in this context because it blocks an infinite regress in which we might be trapped in the attempt to find the data to be explained. If epistemic conservatism is true, the beliefs that we already have can be selected as the data, for they are provided with a minimal degree of justification.

Tommaso Piazza ("Weak Non-Evidentialism”, Chap. 9) rejects evidentialism as conceived by Conee and Feldman. Piazza argues that evidentialists must elucidate the nature of evidence and that, when this is done, they face a forceful dilemma between two alternative responses that are equally unpalatable. If evidentialists endorse a psychologistic ontology of evidence (all evidence is constituted by mental states), their theory does explain intuitive cases 
of perceptual justification, but at the cost of being unable to explain intuitive cases of inferential justification. Conversely, if evidentialists endorse a propositionalist ontology of evidence (all evidence is given by propositions), their theory does explain intuitive cases of inferential justification, but at the cost of being unable to explain intuitive cases of perceptual justification. Piazza then makes an original case-echoing previous conversation involving Feldman, Conee, Williamson, McCain and Littlejohn—-for the conclusion that evidentialists should embrace propositionalism and concede that perceptual doxastic justification is nonevidential. This amounts to accepting — more accurately — a weak form of non-evidentialism according to which $S$ 's belief can be epistemically justified even if it does not fit $S$ 's evidence. Still, according to weak non-evidentialism, $S$ 's belief must nevertheless have a justifier not describable in terms of evidence. (A strong form of non-evidentialism would instead allow $S$ 's belief to be epistemically justified in the absence of any type of justifier.) In the final part of the paper, Piazza suggests that James Pryor's perceptual dogmatism can be seen as a form of weak non-evidentialism.

\section{Part III: Extensions of Non-evidentialist Epistemology}

The third part of the volume contains contributions by Anne Meylan, Jakob Ohlhorst, and

Nikolaj J. L. L. Pedersen. These contributions extend non-evidentialist epistemology to the philosophies of social psychology, psychiatry, and mathematics-areas within which nonevidentialist epistemology have yet to be systematically explored and discussed.

Anne Meylan ("Radical Scepticism, Stereotypes and the Pragmatist Stance", Chap. 10) explores pragmatic anti-sceptical strategies - suggesting that, even if anti-sceptical beliefs are not rational in an evidential way, they may nonetheless exhibit other forms of rationality. Drawing on the literature on stereotypes in social psychology, Meylan suggests that antisceptical beliefs may be instrumentally rational or be underwritten by practical reasons. In 
virtue of doing so she just pushes back against a widely held view in epistemology: practical reasons have no relevance when the purpose is to respond to sceptical arguments. Meylan assumes, for the sake of the argument, that the sceptical conclusion that our ordinary beliefs lack epistemic justification is correct. Yet she suggests that, even so, we can and should entertain our ordinary beliefs for practical reasons, For, we could not have a normal life, if any life at all, without those beliefs. Meylan's argument draws a parallel with well-known moral cases about accurate stereotypes: suppose you have a stereotypical belief $B$ that $X$ is a criminal, which reflects the real distribution of criminals in $X^{\prime}$ 's population, so that $B$ 's probability to be true is quite high. Although you have epistemic reasons to have $B$, in cases like these, it is often true that your practical-specifically, moral-reasons not to have $B$ defeat your epistemic reasons for $B$. Likewise, according to Meylan, your practical reasons to have ordinary beliefs outweigh your (sceptical) epistemic reasons not to have those beliefs. So, practical reasons are relevant when the purpose is to respond to sceptical arguments. In the second part of the paper, Meylan addresses a number of possible objections against her response to the sceptic.

Jakob Ohlhorst (“The Certainties of Delusion", Chap. 11) applies non-evidentialist hinge epistemology to provide a novel account of delusion. Ohlhorst critically draws from previous work of John Campbell and argues that delusions (e.g. delusion of grandeur, delusion of persecution, Capgras delusion, etc.) are a kind of certainties, thus belonging to the same class of doxastic states as Wittgenstein's hinges. In fact, for Ohlhorst, both delusions and hinges are contentful states of which we are so confident that no evidence would change them. Ohlhorst's article proceeds by carefully analysing the notion of delusion and certainty and showing in which aspects delusions resemble certainties. This gives the claim that delusions are certainties some initial plausibility. Ohlhorst then articulates a clear-cut argument for the conclusion that delusions are a kind of certainty. Finally, he defends his view from different criticisms and shows that it is superior to competing views (such as that delusions are sui 
generis states, a particular kind of imagining, false memories, or the symptom of missing hinges). Some of Ohlhorst's salient findings are that both delusions and hinges are beliefs or belief-like states. Delusions are not hinges, however, because they are often simply planted on top of a patient's otherwise intact belief system, whereas hinges are, as it were, the fix axes around which the rest of our belief system rotates. Furthermore, delusions, unlike hinges, hinder our agency - they prevent us from pursuing practical and theoretical projects. So, delusions are of the same doxastic type as hinges, but they fail to fulfil their functional or epistemic role.

Nikolaj J. L. L. Pedersen (“Trusting mathematics: a non-evidentialist, consequentialist epistemology of the foundations of mathematics", Chap. 12) introduces mathematical scepticism, transposing the regress argument known from mainstream epistemology to propositions concerning the satisfiability of mathematical theories. He argues that these propositions are mathematical analogues of the familiar anti-sceptical hypothesis that there is an external world and presents a mathematical version of the regress argument by applying Gödel's second incompleteness theorem and the notion of relative satisfiability. Pedersen investigates non-evidential responses to mathematical scepticism. He introduces his own favoured form of non-evidentialism - a view that combines epistemic consequentialism and a pluralist theory of value. According to Pedersen's consequentialism, acceptance of hinges or cornerstone propositions enjoys a positive epistemic status because it has good epistemic consequences. This idea is understood in terms of (a certain notion of) maximization of epistemic value and is spelled out in detail against the background of a pluralist axiology which incorporates externalist as well as internalist epistemic goods. Pedersen's framework can be deployed to offer a non-evidentialist response to mathematical scepticism as well as scepticism within other domains and, as such, constitutes an alternative to the hinge epistemologies of Wright, Coliva, and Pritchard. At the end of his paper, he argues against Wright's notion of 
entitlement of cognitive project as a viable response to scepticism (mathematical and otherwise), on the grounds that the consequentialist alternative renders entitlement superfluous.

\section{References}

BonJour, L. 1985. The Structure of Empirical Knowledge. Cambridge, Mass.: Harvard University Press.

Burge, T. 1993. “Content Preservation.” The Philosophical Review 104: 457-488.

_. 2003. "Perceptual Entitlement." Philosophy and Phenomenological Research 67: $503-548$.

—. 2020. "Entitlement: The Basis for Empirical Epistemic Warrant." In P. Graham and N. J. L. L. Pedersen (eds.), Epistemic Entitlement, 37-142. Oxford: Oxford University Press.

Clifford, W. K. (1877) “The Ethics of Belief.” In T. Madigan (ed.), The Ethics of Belief and Other Essays, 70-96. Amherst, MA: Prometheus (1999).

Chignell, A. 2018. "The Ethics of Belief”. In E. N. Zalta (ed.), Stanford Encyclopedia of Philosophy. https://plato.stanford.edu/archives/spr2018/entries/ethics-belief/.

Chisholm, R. 1989. Theory of Knowledge ( $3^{\text {rd }}$ ed.). Englewood Cliffs, NJ: Prentice-Hall.

Coliva, A., (2015). Extended Rationality: A Hinge Epistemology. Basingstoke: Palgrave Macmillan. 
—. 2018. "What Anti-Realism About Hinges Could Possibly Be.” In C. Kyriacou and R. McKenna (eds.), Metaepistemology: Realism and Antirealism, PPP. Basingstoke: Palgrave Macmillan.

Conee, E., and Feldman, R. 2004. Evidentialism: Essays in Epistemology. Oxford: Clarendon Press.

—. 2008. "Evidence." In Q. Smith (ed.), Epistemology: New Essays, 83-104. Oxford: Oxford University Press.

David, M. 2001. “Truth as the Epistemic Goal.” In M. Steup (ed.), Knowledge, Truth and Duty, 151-169. New York: Oxford University Press.

—.2005. "Truth as the primary epistemic goal: A working hypothesis." In M. Steup and E. Sosa (eds.), Contemporary Debates in Epistemology, 296-312. Oxford: Blackwell.

Goldman, A. 2001. "The Unity of the Epistemic Virtues.” In A. Fairweather and L. Zagzebski (eds.), Virtue Epistemology: Essays on Epistemic Virtue and Responsibility, 30-49. Oxford: Oxford University Press.

Graham, P. and Pedersen, N. J. L. L. 2020a. Epistemic Entitlement. Oxford: Oxford University Press.

—. 2020b. "Introduction and Overview: Two Entitlement Projects." In Graham and Pedersen (2020a), 1-34.

Harman, G. 1986. Change in View. Cambridge, MA: MIT Press. 
Jenkins, C. S. 2007. "Entitlement and Rationality.” Synthese 157: 25-45.

Lycan, W. 1988. Judgment and Justification. New York: Cambridge University Press.

Lynch, M. P. 2009. Truth as One and Many. Oxford: Oxford University Press.

Moore, G. E. 1939. "Proof of an External World." Proceedings of the British Academy 25: $273-300$.

Moyal-Sharrock, D. 2004. Understanding Wittgenstein's On Certainty. Basingstoke: Palgrave Macmillan.

Pedersen, N. J. L. L. 2009. “Entitlement, Value and Rationality.” Synthese 171: 443-457.

Pritchard, D. 2005. "Wittgenstein's On Certainty and Contemporary Anti-scepticism.” In D. Moyal-Sharrock and W. H. Brenner (eds.), Readings of Wittgenstein's On Certainty, 189-224. London: Palgrave Macmillan.

—. 2012. "Wittgenstein and the Groundlessness of Our Believing." Synthese 12: 255-272.

—. 2015. Epistemic Angst: Radical Skepticism and the Groundlessness of Our Believing. Princeton, NJ: Princeton University Press.

Pryor, J. 2000. "The Skeptic and the Dogmatist.” Nô̂s 34: 517-549.

__. "What's wrong with Moore's argument?” Philosophical Issues 14: 349-378.

Vahid, H. 2004. "Varieties of Epistemic Conservatism." Synthese 141: 97-122. 
Wittgenstein, L. 1969. On Certainty. Oxford: Basil Blackwell.

Wright, C. 2002. “(Anti-)Sceptics Simple and Subtle: G. E. Moore and John McDowell.” Philosophy and Phenomenological Research 65: 330-348.

—. 2003a. "Wittgensteinian Certainties.” In D. McManus (ed.), Wittgenstein and Scepticism, $22-55$.

— 2003 b. "Some reflections on the acquisition of warrant by inference." In S. Nuccetelli (ed.), New Essays on Semantic Externalism and Self-Knowledge, 57-77. Cambridge, MA: MIT Press.

—. 2004. "Warrant for Nothing (and Foundations for Free)?" Proceedings of the Aristotelian Society, Supplementary 78: 167-212.

— 2004. "The Perils of Dogmatism." In S. Nuccetelli and G. Seay (eds.), Themes from G. E. Moore: New Essays in Epistemology and Ethics, 25-48. Oxford: Oxford University Press. —. 2014. "Entitlement (II): Welfare State Epistemology.” In E. Zardini and D. Dodd (eds.), Scepticism and Perceptual Justification, 213-247. New York: Oxford University Press. 